\title{
Investigation of the contact problem for a partial functionally graded layer by using finite element method
}

\author{
A. Polat ${ }^{*}$, Y. Kaya ${ }^{2}$, P. Bora ${ }^{3}$, K. Bendine ${ }^{4}$ and T.Ş. Özşahin ${ }^{5}$ \\ ${ }^{1}$ Munzur University, Construction Technology Department, Tunceli, Turkey \\ 2 Gümüşhane University, Civil Engineering Department, Gümüşane, Turkey \\ 3 Cumhuriyet University, Civil Engineering Department, Sivas, Turkey \\ 4 Djillali Liabès University of Sidi Bel-Abbès, Department of Mechanics, Algeria \\ 5 Karadeniz Technical University, Civil Engineering Department, Trabzon, Turkey
}

\begin{abstract}
The difficulty of producing functionally graded materials (FGM) and the fact that they are more expensive than homogeneous materials emerge as an industrial problem. The starting point of this study is to investigate alternative solution methods that will contribute to the mentioned problem. In parallel, the analysis of the contact problem for a layer, which is loaded by a rigid block and resting on the elastic half plane, is presented in this paper. Only the area under the block is considered as FGM, the other parts are considered homogeneous material, unlike the studies in the literature. There is no analytical solution for this study and it is compared with the solution which is completely functionally graded (FG) layer in the literature by using finite element method (FEM). Material properties of the FG layer are defined by the macro added to the ANSYS program. The analysis for the partial FG layer were compared with the completely FG layer analysis as figures and tables, and as a result it was predicted that partial FGM could be used for the static problems and may also be practical applications in the industry.
\end{abstract}

\section{Keywords}

Partially functionally graded materials; Contact problem; Homogeneous materials; Finite element method; Stress distribution

Received: 16 November 2018; Accepted: 24 December 2018

ISSN: 2630-5763 (online) C 2018 Golden Light Publishing ${ }^{\circledR}$ All rights reserved.

\section{Introduction}

Contact problem studies first started in 1882 by Heinrich Hertz. These studies get earned big developments from that time and they are still keeping their importance. The fact that many structural and mechanical system elements are in contact with each other is one of the most important reasons for this condition. These studies, which in the past have made important contributions in the fields of highways, railways, foundations, fuel oil tanks, etc., have shown developments with the gradual release of homogeneous layer or types of soil over time to functionally graded (FG) layers or soils, and now they have found a broader scope of application in aviation, electronics, energy, chemical engineering and optical materials [1].

Functionally graded materials (FGM) are the materials that consist mostly of two or more materials and the volume fractions continuously change along certain directions. While the absence of separate internal borders effectively reduces the

\footnotetext{
Corresponding author

E-mail: apolat80@gmail.com
} 
interfacial stresses, the gradual change of the material properties is very advantageous in that the components achieve the desired performance.

Comez [2] was examined the contact problem of a functionally graded layer loaded by a cylindrical punch which applied a concentrated force in the vertical direction and supported by Winkler foundation. Calculations were made assuming that the Poisson's ratio was constant and that the modulus of elasticity changed over the thickness of the layer. Güler et al. [3] solved the frictional contact problem with analytical and Finite Element Method (FEM) for a FG orthotropic medium. There are many studies about FG soil in the literature [4-14]. Due to the long duration of the analytical solution of the contact problem and the advances in computer technology, a number of approximate solution methods have been developed for the solution of contact problems. FEM is one of the most commonly used method. Firstly, [15] developed a solution based on FEM for the plane contact problem of elastic bodies. Then, many researchers have solved the contact problems by using FEM [16-25]. Besides, in recent years, the studies have increased that analytical results are compared with FEM results of contact problems for FG layers [26-32].

Despite the advantages of FGMs, there are a number of disadvantages such as feasibility and cost. In this work, it was assumed that only the area under the block is functionally graded. The results were compared with the problem [13]. The main purpose of the study is, to examine the differences between using FGM only in areas of contact interaction and the use of FGM in the entire layer in static problems.

\section{Definition of the problem}

The continuous contact problem of a composite layer which has a height of " $\mathrm{h}$ " and resting on an elastic half-plane, was solved by using FEM. The composite layer consists of homogenous and FG parts. For the layer loaded with "2a" wide rigid block, only the bottom of the block is FG, and the rest of the layer is considered as homogeneous. FG part is considered as isotropic and non- homogeneous material and the shear modulus of the layer is $\mu_{1}(y)=\mu_{0} e^{\beta y}$, while its density varies in the form of $\rho_{1}(y)=\rho_{0} e^{\gamma y}$. Where, $\mu_{0}$ and $\rho_{0}$ represents the shear modulus and density on the upper surface of the FG layer, respectively. $\beta$ and $\gamma$ are the inhomogeneity parameters expressing change in depth. For all analyzes, the material properties of the homogenous parts of the layer were selected same as the material properties of the bottom surface of the FG layer. In addition, it was assumed that all surfaces were frictionless in the problem and the body forces of homogeneous part of layer were considered as $\rho g h$ in the solution. Where, $\rho$ is the mass density of homogeneous layer, $g$ is the gravity acceleration. The geometry of the contact problem is given in Fig. 1.

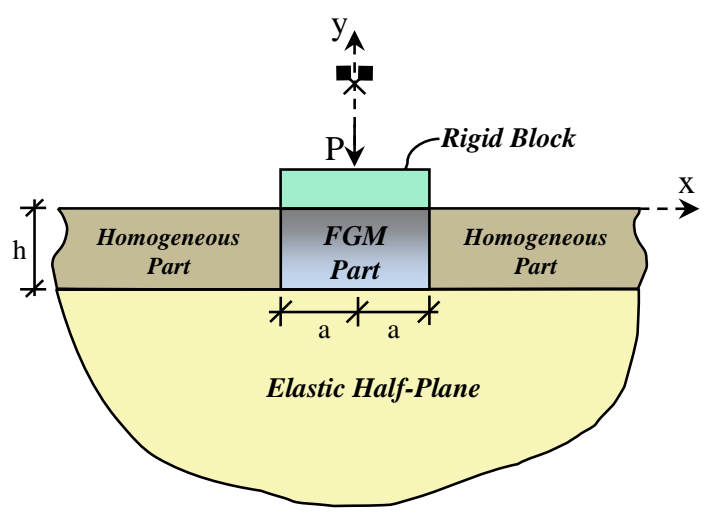

Fig. 1. Geometry of the problem

\section{Solution with finite element method}

Finite element method (FEM) is a method developed for solving problems in various subjects such as elasticity, structural analysis, thermal analysis, encountered in various engineering branches such as machinery, construction and aerospace engineering. Basic approach of FEM is to convert any continuous magnitude, such as temperature, pressure, strain, deformation or displacement into a model formed by the joining of small and continuous parts. The main structure is divided into many elements whose behavior has already been determined in FEM. Equation system are obtained by reassembling the elements at the so- 
called "node". In this process called mesh, the problem is simplified by processing on many small subparts instead of the whole of the problem. In this paper, the finite element model and analysis of the problem was performed by using ANSYS [33] package program. In modeling, the body forces of the layers were considered, but the friction forces between the block and the composite layer and the elastic plane were neglected. Linear, elastic and isotropic material were used in all parts of the model. Determining the element type is important in terms of obtaining correct results in solving the problem. Due to this study is a static and 2dimensional plane problem, PLANE183 with 8 nodes is used as the element type. The PLANE183 has second order displacement behavior and is very suitable for modeling irregular networks. In addition, for each node, it has a degree of freedom, in the $\mathrm{x}$ and $\mathrm{y}$ directions, and has no freedom of rotation.

In order to define the material properties of the FG part of the layer according to the exponential change and the mesh process, a macro was used that was specifically added into the ANSYS program [30]. In this macro, the material properties are defined as follow:

*create, fgm_material

/nopr

y_coord $=\arg 1$

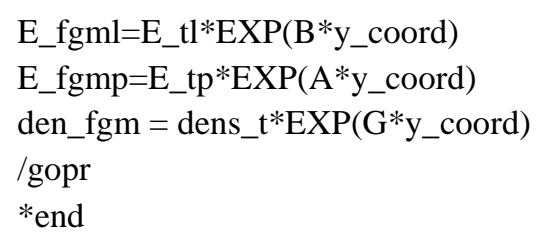

Where, the * create command is used to create a macro for a layer of FGM, and y_coord = sets a variable named $\arg 1$. In the study, while modeling, the surface-surface contact model was used because of the solution of the points in case of not overlapping of the nodes. In 2D modeling, contact pair is formed, the target surface is defined by the TARGE 169 element and the contact surface by the CONTA 172 element. Non-deformed parts in other words the more rigid parts are selected as the target from contacting surfaces. The elements TARGE169 and CONTA172 are elements comprising three nodes, the nodes overlapping the nodes on the surface of the PLANE 183 element. Various contact algorithms such as Penalty Method, Lagrange Multiplier Method and Augmented Lagrange Method are available depending on the type of problem in solving elastic contact problems within the ANSYS program. In this study, the Augmented Lagrangian Method, which uses the total potential energy theorem as the contact algorithm and gives better and faster results than the other algorithms, is preferred. The finite element model of the problem is as in Fig. 2.

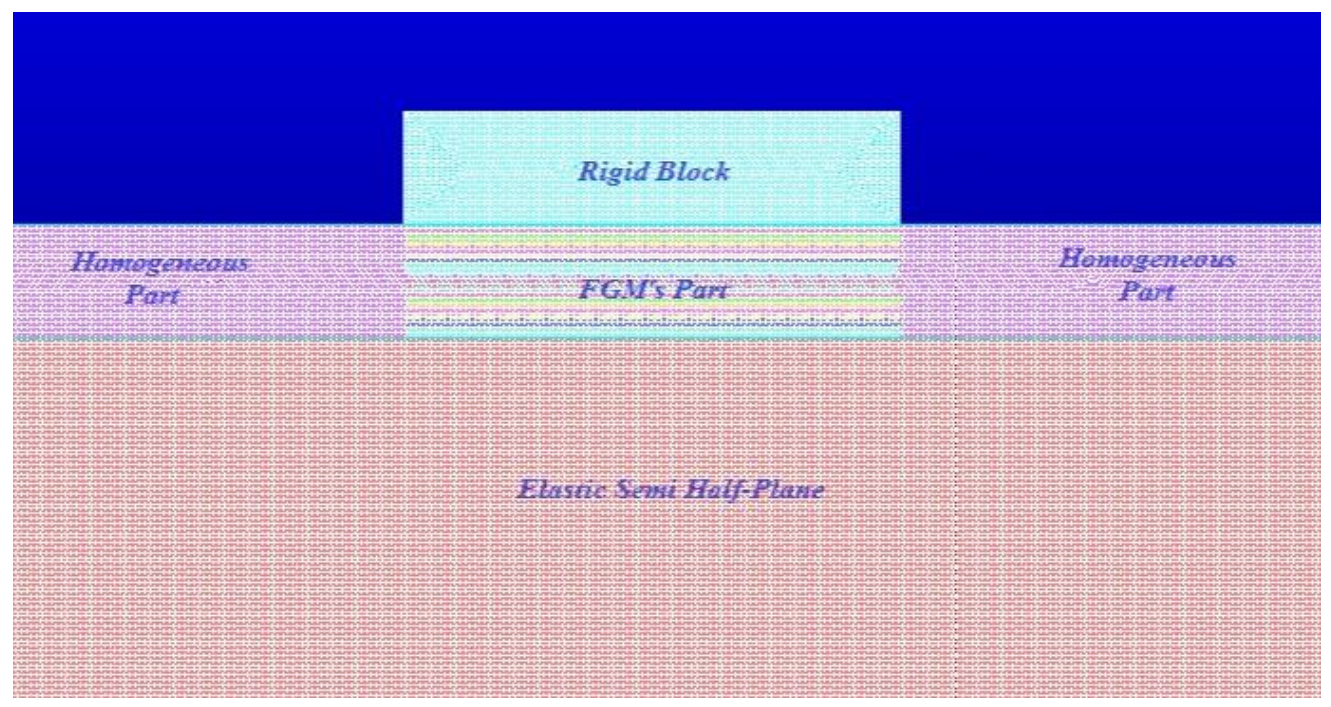

Fig. 2. Finite element geometry of the problem 


\section{Results and discussions}

In this paper, a continuous contact problem for a layer, partly composed of FG material, was performed using FEM. This study has a big difference from the previous studies with its composite property. The examined layer resting on elastic plane was considered as FGM only under the block and all other parts were accepted as homogeneous. Therefore, the problem was solved for different shear modulus $(\mu)$ by using stiffness parameters $(\beta \mathrm{h})$, block widths $(\mathrm{a} / \mathrm{h})$ and density parameters $(\gamma \mathrm{h})$. The results were compared with the analytical solution which was obtained by Oner et al. [13] and they are given as graphs and tables comparatively.

The dimensionless contact stress distribution obtained based on the change of the block width is given in Fig. 3. In this analysis, the bottom surface stiffness of the layer is greater than the upper surface stiffness. In Fig. 4, various analyzes are performed depending on the stiffness parameter. Where, three different conditions are investigated for FG layer. Firstly, the top of the layer is 5 times rigid than the bottom, the second is thought to be homogeneous and the third is 5 times less rigid. Fig. 5 shows the ratio of shear modulus of FG layer to that of elastic half plane. Where, the shear modulus for FG layer is considered to the shear modulus of the bottom surface. In this analysis, the bottom surface of the FG layer is chosen as 2 times rigid compared to the upper surface. In Figs. 3 and 5, it is observed that the results obtained from the partial FGM layer were very close to the results obtained with the completely FGM layer. However, differences are observed in Fig. 4. If the stiffness increases from top to bottom, the under-block stress is lower for partial FGM. Nevertheless, if the stiffness decreases from top to bottom, there is an increase in the stresses under the block compared to completely FGM.

Figs. 6-8 shows the dimensionless stress distributions that occur between the elastic semiinfinite plane and the layer. In Fig. 6, the dimensionless contact stress obtained by increasing or decreasing the block width was examined and compared with the analytical result. In Figs. 7 and
8, for the inhomogeneity parameters $\beta \mathrm{h}$ and $\gamma \mathrm{h}$, partial FGM and full FGM were compared and stress distributions were shown. As can be seen from Figs. 6 and 7, similar to the stress distributions under the block, the results of the stress distribution between the elastic plane and the layer are too close to each other.

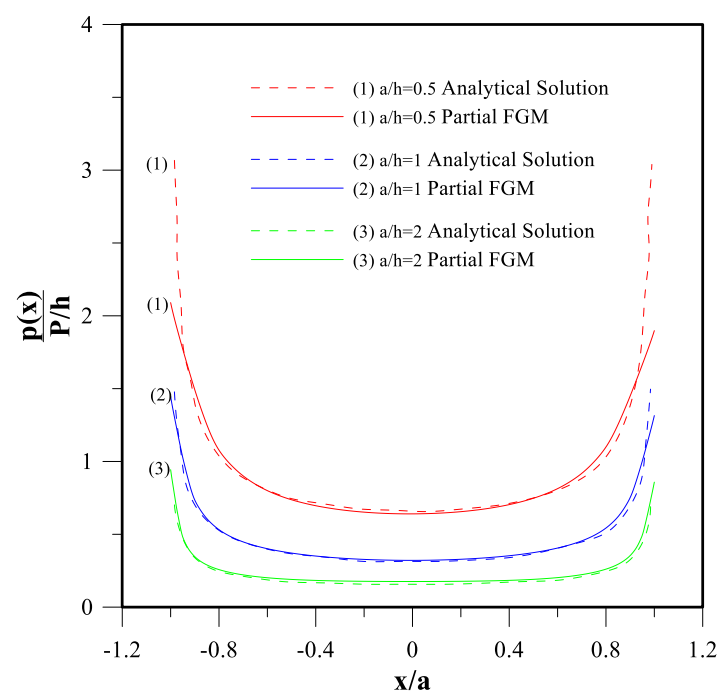

Fig. 3. Dimensionless stress distribution under block depending on block width $(\mathrm{a} / \mathrm{h})\left(\kappa_{1}=\kappa_{2}=2, \beta \mathrm{h}=-0.6931\right.$, $\left.\mu_{-h} / \mu_{2}=1, h=1, \mu_{0}=1, y=0\right)$

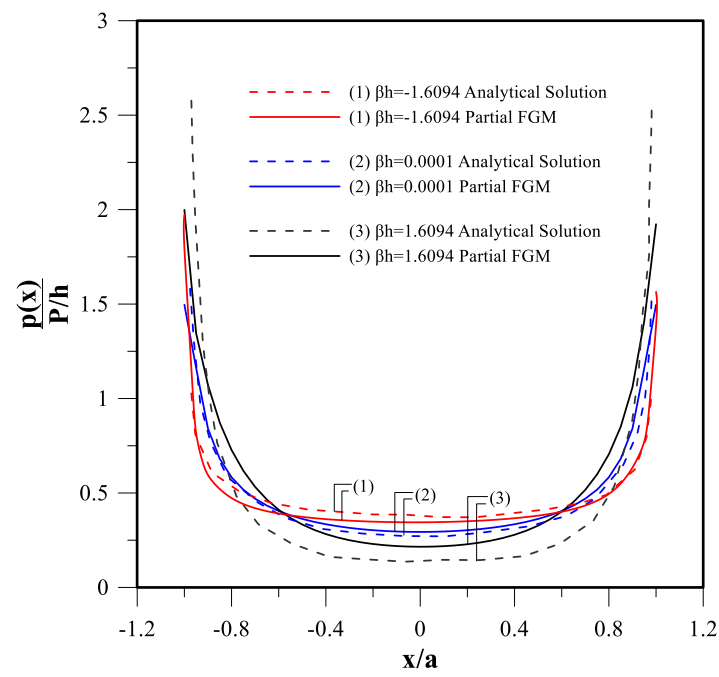

Fig. 4. Dimensionless stress distribution under block depending on inhomogeneity parameter $(\beta \mathrm{h})\left(\kappa_{1}=\kappa_{2}=2\right.$, $\mathrm{a} / \mathrm{h}=1, \mu_{-\mathrm{h}} / \mu_{2}=1, \mathrm{~h}=1, \mu_{0}=1, \mathrm{y}=0$ ) 


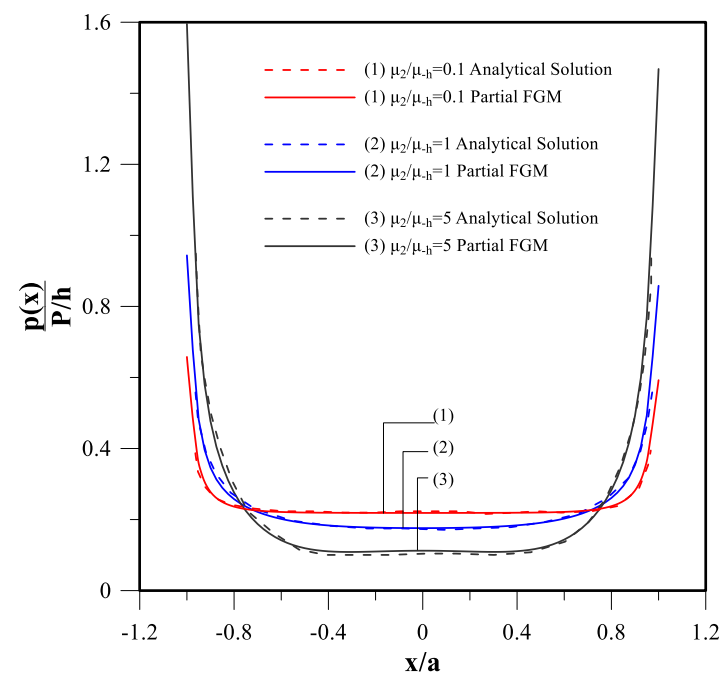

Fig. 5. Dimensionless stress distribution under block depending on shear modulus $(\mu)\left(\kappa_{1}=\kappa_{2}=2, a / h=2, \beta h=\right.$ 0.6931, $\mathrm{h}=1, \mu_{0}=1, \mathrm{y}=0$ )

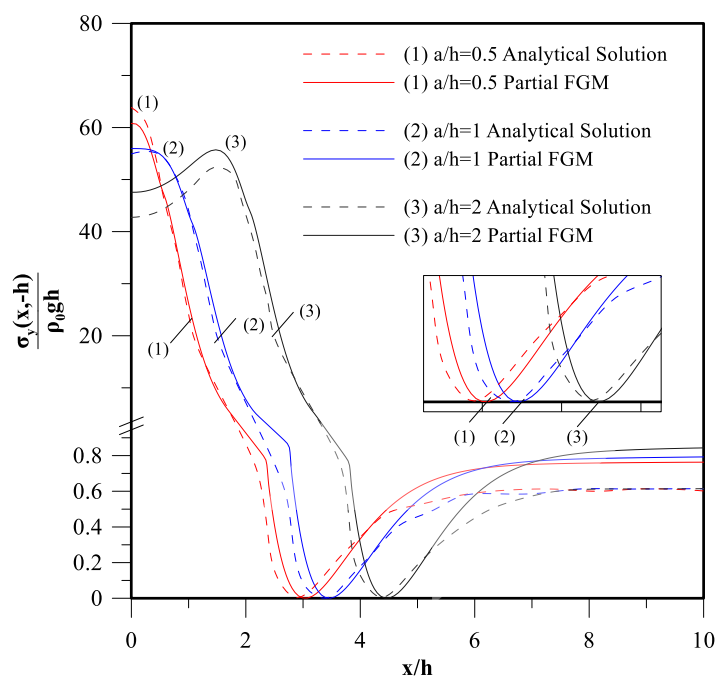

Fig. 6. Variation of the initial separation point and the initial separation distance depending on the block width $(\mathrm{a} / \mathrm{h})\left(\kappa_{1}=\kappa_{2}=2, \beta \mathrm{h}=-0.6931, \gamma \mathrm{h}=1.0986, \mu-\mathrm{h} / \mu_{2}=1, \mathrm{~h}=1\right.$, $\left.\mu_{0}=1, y=-h\right)$

However, Fig. 8 is examined, if density of bottom surface of the layer is higher than the upper surface, the stresses are lower in the case of using partial FGM. When density of upper surface of the layer is higher than, the completely FGM results are better.

Figs. 9 and 10 show the dimensional contact and $\sigma_{y} / \rho_{0} g h$ stresses obtained from finite element analysis.

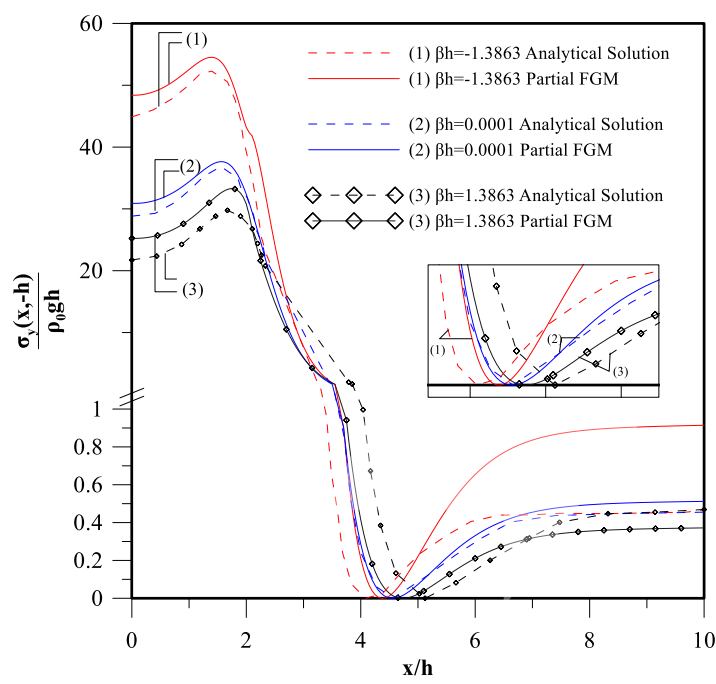

Fig. 7. Effect of the inhomogeneity parameter $(\beta \mathrm{h})$ on the stress distribution $\left(\kappa 1=\kappa 2=2, \mathrm{a} / \mathrm{h}=2, \gamma \mathrm{h}=1.6094, \mu-\mathrm{h} / \mu_{2}=1\right.$, $\mathrm{h}=1, \mu_{0}=1, \mathrm{y}=-\mathrm{h}$ )

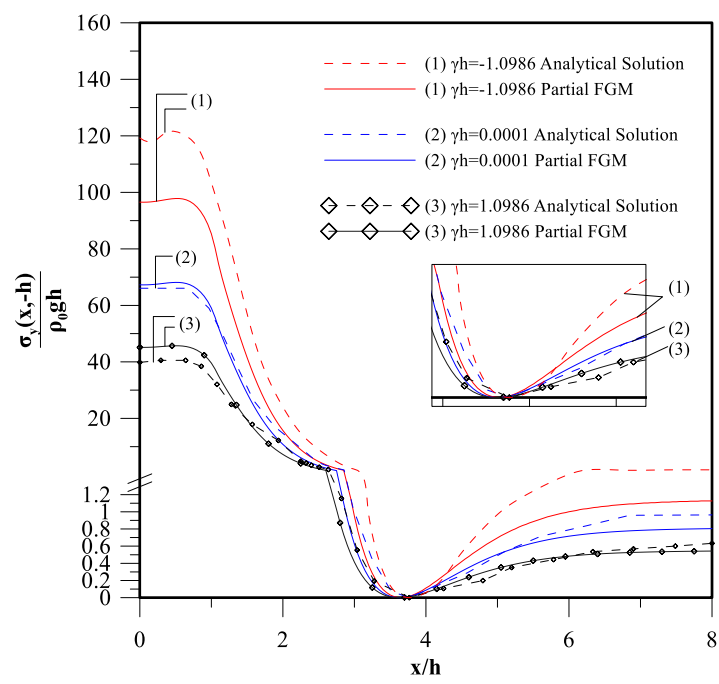

Fig. 8. Effect of change of density parameter $(\gamma \mathrm{h})$ on initial separation point and distance $(\kappa 1=\kappa 2=2, \mathrm{a} / \mathrm{h}=1$, $\left.\beta \mathrm{h}=0.6931, \mu_{-\mathrm{h}} / \mu_{2}=1, \mathrm{~h}=1, \mu_{0}=1, \mathrm{y}=-\mathrm{h}\right)$

Table 1 shows the effects of the stiffness parameter $(\beta h)$ and density parameter $(\gamma \mathrm{h})$ on the initial separation loads and distances. In all analyzes, the material properties of the homogeneous layer are considered equal to the subsurface properties of the FG layer. In the case where the bottom surface of the FG layer is more rigid, the initial separation point is occurred further away compared to the completely FG layer. When the density and 
stiffness of bottom surface of FG layer is increased together, the initial separation load is close to each other. If the bottom surface of FG layer is selected to have high stiffness and low density, the partial FG layer is more easily separated from the elastic half plane compared to completely FG layer. When density of bottom surface and stiffness of upper surface of FG layer are selected to be high, the separation occurred closer to the block. However, the load that will start the separation has been too high.

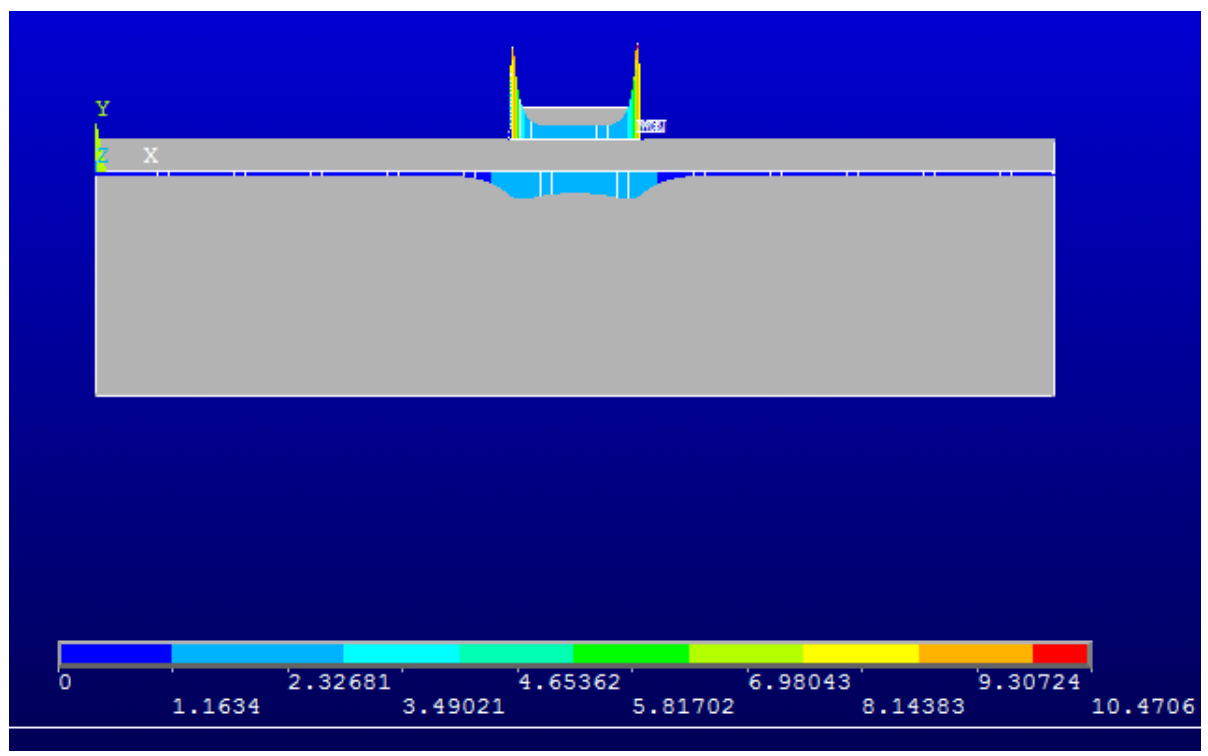

Fig. 9. Stress distribution under the block after finite element analysis of the problem

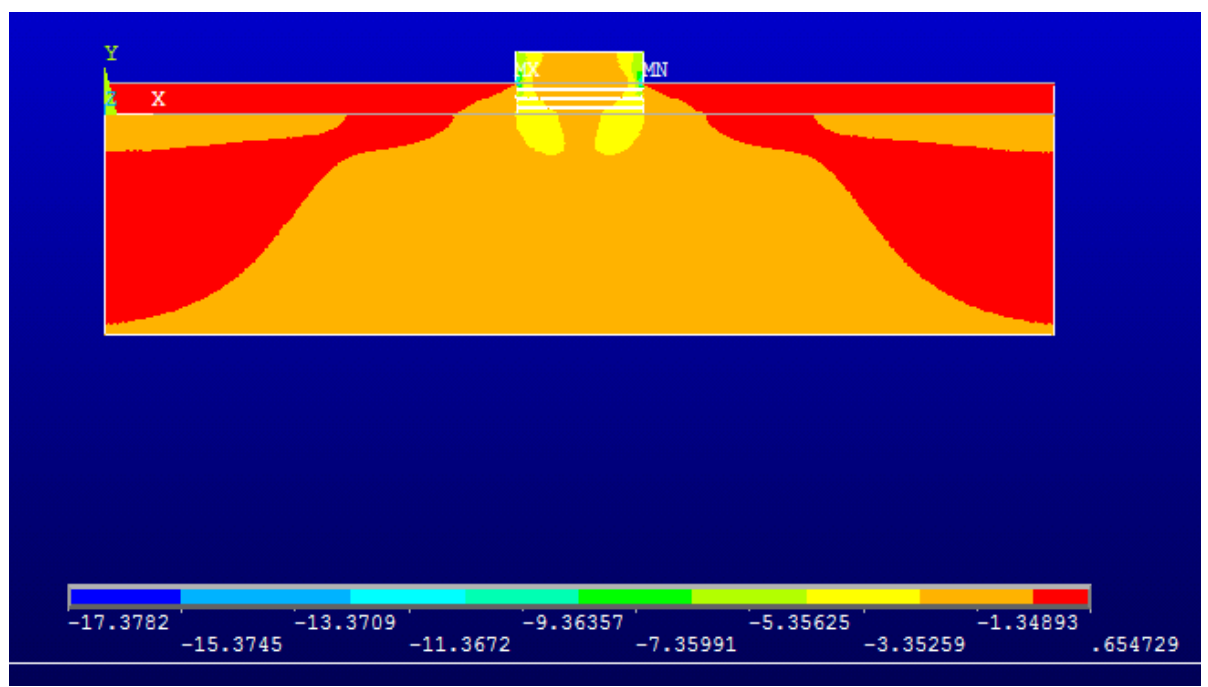

Fig. 10. Dimensionless $\sigma_{y} / \rho_{0} g h$ stress distribution after finite element analysis of the problem 
Table 1. The effect of the changes in inhomogeneity parameters $(\beta h, \gamma h)$ on the initial separation loads and distances $\left(\kappa_{1}=\kappa_{2}=2, \mathrm{a} / \mathrm{h}=2, \mu_{-\mathrm{h}} / \mu_{2}=1, \mathrm{~h}=1, \mu_{0}=1, \mathrm{y}=-\mathrm{h}\right)$

\begin{tabular}{|c|c|c|c|c|c|c|c|c|c|c|c|c|}
\hline \multirow{4}{*}{$\gamma \mathrm{h}$} & \multicolumn{12}{|c|}{$\mathrm{Bh}$} \\
\hline & \multicolumn{4}{|c|}{-1.3863} & \multicolumn{4}{|c|}{0.0001} & \multicolumn{4}{|c|}{1.3863} \\
\hline & \multicolumn{2}{|c|}{ Present } & \multicolumn{2}{|c|}{$\begin{array}{c}\text { Öner et al. } \\
\text { [13] }\end{array}$} & \multicolumn{2}{|c|}{ Present } & \multicolumn{2}{|c|}{$\begin{array}{c}\text { Öner et al. } \\
\text { [13] }\end{array}$} & \multicolumn{2}{|c|}{ Present } & \multicolumn{2}{|c|}{$\begin{array}{c}\text { Öner et al. } \\
\text { [13] }\end{array}$} \\
\hline & $\mathrm{X}_{\mathrm{cr}}$ & $\lambda_{\text {cr }}$ & $\mathrm{X}_{\mathrm{cr}}$ & $\lambda_{\mathrm{cr}}$ & $\mathrm{X}_{\mathrm{cr}}$ & $\lambda_{\text {cr }}$ & $\mathrm{X}_{\mathrm{cr}}$ & $\lambda_{\mathrm{cr}}$ & $\mathrm{x}_{\mathrm{cr}}$ & $\lambda_{\text {cr }}$ & $\mathrm{X}_{\mathrm{cr}}$ & $\lambda_{\mathrm{cr}}$ \\
\hline-1.0986 & 4.35 & 804.83 & 4.14 & 829.35 & 4.50 & 967.82 & 4.53 & 593.48 & 4.70 & 1139.82 & 5.12 & 508.20 \\
\hline 0.0001 & 4.35 & 264.64 & 4.14 & 455.55 & 4.50 & 318.85 & 4.53 & 325.99 & 4.70 & 376.35 & 5.12 & 279.15 \\
\hline 1.0986 & 4.35 & 79.31 & 4.14 & 276.45 & 4.50 & 96.58 & 4.53 & 197.83 & 4.70 & 115.06 & 5.12 & 169.40 \\
\hline
\end{tabular}

\section{Conclusions}

In this paper, unlike the literature; taking into consideration the production difficulties and costs of FG materials, the feasibility of using FG material only in contact regions was investigated instead of the whole layer. The analysis of the layers consisting of both partially and completely FGM are examined with the figures and the table,

- When stress distribution under the block is examined, no significant difference is observed for block width and shear modulus changes. However, differences are observed for the stiffness parameter. If the stiffness increases from top to bottom, the underblock stress is lower for partial FG layer. In this case, it can be said that it is more advantageous if the layer is partial FGM. However, if the stiffness decreases from top to bottom, there is an increase in the stresses under the block compared to completely FG layer. For this condition, it is more advantageous to use completely FG layer.

- When the stress distributions between the composite layer and the elastic half plane are examined, there are no significant differences for the block width and stiffness parameter. When the change of the density parameter is examined, if density of bottom surface of the layer is higher than the upper surface, the stresses are lower in the case of using partial FG layer and it is advantageous for this condition. If the density of upper surface is higher, the completely FG layer results are better.
- If the upper surface stiffness and the bottom surface density of the FG layer are considered higher, it can be seen that the layer is rather difficult to separate from the elastic plane compared to completely FG layer. However, for FG layer; if bottom surface is more rigid and the upper surface is denser, the separation is much easier.

- When the difficulties in the production process of FGMs and economic factors are considered, with this study, it was concluded that partial FGM can be used only in the contact regions with static problems. Hence, it is thought that effective results can be obtained in less time and with less cost in industrial areas.

\section{References}

[1] Koizumi M (1997) FGM activities in Japan. Composite Part B 28B: 1-7.

[2] Çömez I (2013) Contact problem of a functionally graded layer resting on a Winkler foundation. Acta Mechanica 224: 2833-2843.

[3] Güler MA, Kucuksucu A, Yılmaz KB, Yıldırım B (2017) On the analytical and finite element solution of plane contact problem of a rigid cylindrical punch sliding over a functionally graded orthotropic medium. International Journal of Mechanical Sciences 120: 12-29.

[4] Güler MA, Erdogan F (2004) Contact mechanics of graded coatings. International Journal of Solids and Structures 41: 3865-3889.

[5] Kee LL, Wang YS (2006) Two-dimensional contact mechanics of functionally graded materials with arbitrary spatial variations of material properties. International Journal of Solids and Structures 43: 5779-5798. 
[6] Güler MA, Erdogan F (2007) The frictional sliding contact problems of rigid parabolic and cylindrical stamps on graded coatings. International Journal of Mechanical Sciences 49: 161-182.

[7] Yang J, Ke LL (2008) Two-dimensional contact problem for a coating graded layer substrate structure under a rigid cylindrical punch. International Journal of Mechanical Sciences 50: 985-994.

[8] Choi HJ (2009) On the plane contact problem of a functionally graded elastic layer loaded by a frictional sliding flat punch. Journal of Mechanical Science and Technology 23: 2703-2713.

[9] Apatay T. Crack and contact problems in functionally graded coatings. PhD Thesis. Gazi University, 2010.

[10] Nie GJ, Zhong Z, Chen S (2013) Analytical solution for a functionally graded beam with arbitrary graded material properties. Composites Part B: Engineering 44: 274-282.

[11] Çömez I (2015) Contact problem for a functionally graded layer indented by a moving punch, International Journal of Mechanical Sciences 100: 339-344.

[12] Ramirez F, Heyliger PR, Pan E (2006) Static analysis of functionally graded elastic anisotropic plates using discrete layer approach. Composites Part B: Engineering 37: 10-20.

[13] Öner E, Adiyaman G, Birinci A (2017) A continuous contact problem of a functionally graded layer resting on an elastic half-plane. Archives of Mechanics 69(1): 53-73.

[14] Adıyaman G, Öner E, Birinci A (2017) Continuous and discontinuous contact problem of a functionally graded layer resting on a rigid foundation. Acta Mechanica 228(9): 3003-3017.

[15] Chan, SK, Tuba IS (1971) A finite element method for contact problems of solid bodies-1: Theory and validation, International Journal of Mechanical Sciences 13: 615-625.

[16] Sachdeva TD, Ramakrishnan CV (1981) A finite element solution for the two-dimensional elastic contact problems with friction. International Journal for Numerical Methods in Engineering 17: 1257-1271.

[17] Landerberger A, El-Zafrany A (1999) Boundary element analysis of elastic contact problems using gap finite elements. Computers and Structures 71: 651-661.
[18] Jackson RL, Green I (2005) A finite element study of elasto-plastic hemispherical contact against a rigid flat. ASME Journal of Applied Mechanics 127: 343-354.

[19] Sezer S. An evaluation of ANSYS contact elements. MSc Thesis. Louisiana State University, 2005.

[20] Brezeanu LC (2014) Contact stresses: Analysis by finite element method (FEM). Procedia Technology 12: 401-410.

[21] Birinci A, Adıyaman G, Yaylacı M, Öner E (2015) Analysis of continuous and discontinuous cases of a contact problem using analytical method and FEM. Latin American Journal of Solids and Structures 12: 1771-1789.

[22] Oner E, Yaylacı M, Birinci A (2015) Analytical solution of a contact problem and comparison with the results from FEM. Structural Engineering and Mechanics 54: 607-622.

[23] Rashid A. Finite element modeling of contact problems. PhD Thesis, Linköping University, 2016.

[24] Kaya Y, Polat A, Ozsahin TŞ (2018) Comparison of FEM solution with analytical solution of continuous and discontinuous contact problem. Sigma Journal of Engineering and Natural Sciences 36(4):977-992.

[25] Polat A, Kaya Y, Ozsahin TŞ (2018. Analysis of frictionless contact problem for a weighted layer on an elastic half plane using FEM (in Turkish). Düzce University Journal of Science and Technology 6(2): 357-368.

[26] Schwarzer N, Djabella H, Richter, Arnell RD (1995) Comparison between analytical and FEM calculations for the contact problem of spherical indenters on layered materials. Thin Solid Films 270: 279-282.

[27] Kaman MO, Çetişli F. Crack problem of cylinder covered with functionally graded material (in Turkish). Electrical-Electronics and Computer Symposium 5-7 Oct 2011, Elazığ, Turkey.

[28] Abhilash MN, Murthy H (2014) Finite element analysis of 2D elastic contacts involving FGMs. International Journal for Computational Methods in Engineering Science and Mechanics 15: 253257.

[29] Turan M, Adiyaman G, Kahya V, Birinci A (2016) Axisymmetric analysis of a functionally graded layer resting on elastic substrate. Structural Engineering and Mechanics 58: 423-442. 
[30] Polat A, Kaya Y, Özşahin TŞ. Analysis of continuous contact problem in functionally graded layer using finite element method (in Turkish). 20. National Mechanical Congress 5-9 Sep 2017, Bursa, Turkey.

[31] Sofiyev AH, Osmancelebioglu E (2017) The free vibration of sandwich truncated conical shells containing functionally graded layers within the shear deformation theory. Composites Part BEngineering 120: 197-211.

[32] Polat A, Kaya Y, Özşahin TŞ (2018) Analytical solution to continuous contact problem for a functionally graded layer loaded through two dissimilar rigid punch. Meccanica 53(14): 35653577.

[33] ANSYS, Swanson Analysis Systems Inc., Houston PA, USA, 2015. 